\title{
Relation between Conditioned Stimulus-Elicit Responses and Unconditioned Response Diminution in Long-Interval Human Heart-Rate Classical Conditioning
}

\author{
José L. Marcos and Jaime Redondo \\ University of La Coruña
}

Previous research on electrodermal conditioning suggests that the conditioned diminution of the unconditioned response (UR) has an associative basis. The aim of this experiment was to test whether this phenomenon also occurs in heart rate (HR) classical conditioning. For this purpose, a differential classical conditioning was performed. The conditioned stimuli (CSs) were geometrical shapes (the CS+ was a square and the CS- was a triangle) displayed on a computer screen and a burst of white noise was used as unconditioned stimulus (US). For analysis of the conditioned response (CR) components, an interval between CS+ and US of 8 seconds was used. After the acquisition phasc, participants were tested using trials with the US preceded either by a CS+, a CS-, or a neutral stimulus (a circle). The results showed conditioned diminution of the UR and suggest that the second heart rate deceleration component $(D 2)$ is sesponsible for the occurtence of this phenomenon.

Key words: classical conditioning, heart rate, anconditioned response, conditioned response

\begin{abstract}
Investigaciones previas en condicionamiento electrodérmico indican que la disminución condicionada de la respuesta incondicionada $(\mathrm{Rl})$ posee una base asociativa. El objetivo de este experimento fue estudiar si este fenómeno ocurre también en el condicionamiento clásico de la tasa cardíaca (TC). Para ello se llevó a cabo un condicionamiento clásico diferencial. Los estímulos condicionados (ECs) eran figuras geométricas (el EC+ era un cuadrado y el EC- un triángulo) mostradas en la pantalla de un ordenador y como estímulo íncondicionado (El) se utilizó una explosión de ruido blanco. Para permitir el análisis de los componentes de la respuesta condicionada $(\mathrm{RC})$ se estableció un intervalo entre el $E C+$ y el El de 8 segundos. Tras la fase de adquisición, los sujetos pasaron a la fase de prueba en la que se presentaban cinco ensayos en los que el El era precedido por un EC+, un EC- o un estímulo neutro (un círculo). Los resultados mostraron disminución condicionada de la Rl y sugieren que este fenómeno se debe al componente de deceleración secundaria de la tasa cardíaca (D2).

Palabras clave: condicionamiento clásico, tasa cardiaca, respuesta incondicionada. respuesta condicionada
\end{abstract}

This work was supported by a grant from the XUNTA DE GALICIA (XUGA 10604B98)

Correspondence concerning this article should be addressed to José I. Marcos. Departamento de Psicología. Campus de Elviña, s/n. Universidad de La Coruña. 15071 La Coruña (Spain). E-mail: jlmarc@udc.es 
Traditionally, most studics about classical conditioning focus on the study of conditioned response (CR) as a new response that develops during conditioning trials. From this perspective, the stimulus substitution paradigm (S-R) assumed that the CR was atso similar to the unconditioned response (UR) except, perhaps, in amplitude (Furedy, 1992; Marcos, 1997). However, as a consequence of conditioning taking place, another phenomenon appearud, no less interesting yed not investigated as much: UR modulation, that is to say, diminution or facilitation of this response that takes place independently of the nonassociative effects of habituation or sensitization, respectively. When an aversive unconditioned stimulus (US) is used, reduced UR has been frequently observed after repeated pairing of a conditioned stimulas (CS) with the US (c.g., Baltissen, 1998; Baxtcr, 1966; Kimmel, 1966, 1967; Lykken, 1959; Marcos \& Redondo, $1999 \mathrm{a}, 1999 \mathrm{~b}$; Redondo, \& Marcos, 2000; Taylor, Carlson, lacono, Lykken, \& McGue, 1999). This phenomenon has been called "conditioned dimimution of the UR" (Kimble \& Os1. 1961), and a broad range of explanations has been offered.

Marcos and Redondo (1999a) studied whether the conditioned diminution of the UR was a phenomenon of associative basis. Participants received discrimination training in which one CS was reinfored (CS+/US) and a second CS was nonreinlored (CS-). After the discrimination training phase, participants were lested introducing five presentations of cach CS followed by the US, and five presentations of a neutral stimulus (NS) lollowed by the US. The results indicated that the skin conductance response (SCR) amplitude of the UR was lower when the US was preceded by the CS+ than when the US was preceded by the CS- or the NS. However, NS/US presentations elicited URs of greater amplitude than those of the CS-/US presentations. These results were explained in terms of the orienting reflex (OR) reinstatement, although a moderate level of discriminalive control over the conditioned diminution of the UR was also found. thus indicating that this phenomenon can have atr associative basis.

In this experiment. we apply the design used in Marcos and Redondo (1999a) but with heart rate (HR) as dependent variable. HR was closen because the $\mathrm{CR}$ in $\mathrm{HR}$ conditioning with long intervals presents components that are antagonistic to the UR. Thus, the UR elicited by an aversive US is accelerative, whereas the $C R$ shows accelerative and decelerative eomponents. The role of the antagonistic CRs can be studied in the explanation of the conditioned diminution of UR in HR. In the SCR classical conditioning. the components of CR folfow the same direction as the UR. However, in HR conditioning, CR components ane typically observed as a trjphasic response complex during the interstimulus inlerval (Hugdahl, 1995a, 1995b; Obrist, Webb, \& Sutlerer, 1969). This triphasic curve (see Figure 1) is also observed in the typical recordings of the two-stimulus paradigm (S1-S2), for example, during an information- processing sequence from stimulus input to the execution of a response, stch as the performance of at raction-time lask requiring the participant to press a button in response to a stimulus (c.g.. Ilugdabl. 1995a: Koers, Gailiard, \& Mudder, 1997; Otten, Gaildad, \& Wientjes, 1995 ).

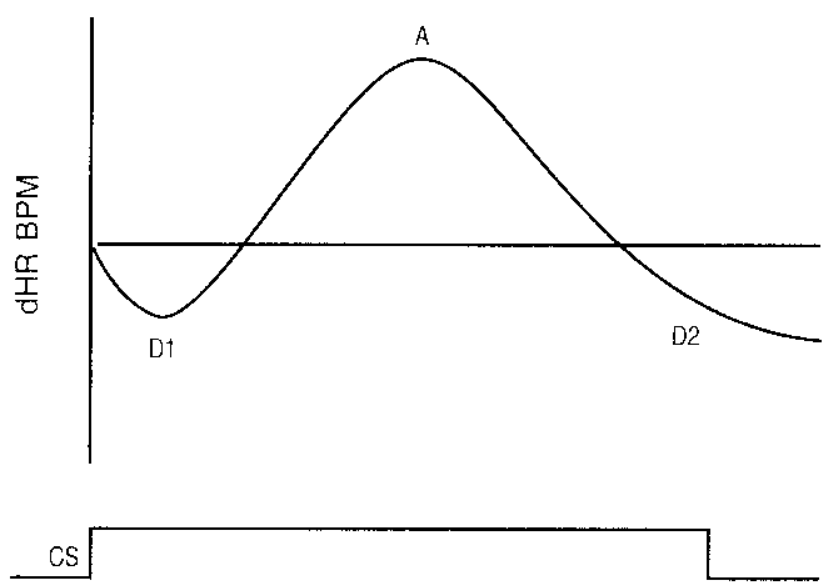

Figrore I. IR triphasic curve and CR components with an interstimulus interval of $8 \mathrm{~s}$. $D /$ (first deceleration component). $A$ (acceletative component). D2 (second deccleration component).

When an 8-second (s) interstimulus interval (ISI) is used. there is usually an initial deceleration $(D /)$ to 2 seconds after CS onset, followed by all acceleration $(A)$ lor aboul 3 to 6 seconds. with a second deceleration (D2) occurring a few seconds before the US is presented (Bohlin \& Kjelbers, 1979; Hugdahl, 1995b). The DI component is associated with the cognitive processes of focusing attention and orienting to the stimulus (1lugdahl, 1995a). In a classical conditioning situation, the acceleration in response to the CS may be taken as an index of the conditioned response (Olman. 1983). The D2 component is related to anticipation of a second stimulus and, therefore, the peak of this component will depend on the ISI employed (I Iugdahl, I995a).

Deceleration maly be coupled to an "open altentional stance," whereas acceleration is related to a "closed attentional stance" (Venables, 1991). These concepts atre similat to the notions of "sensory intike" and "environmental rejection" (Lacey, 1967) and to the difference in heart-rate responses to orienting versus defensive (DR) response stimuli (Graham, 1973; see Hugdahl. 1995a, for a review).

The purpose of the present work was, on the one hand. to study whether in human HR conditioning the plienomenon of conditioned diminution of the UR takes place and, on the other hand, to analyze the possible role that CR components play in the explanation of this phenomenon. With the aim of assessing the presence of discriminative control by the CS, HR was measured within a differential classical conditioning partadigm. The hypothesis tested were: 
(a) that preecding the US by a CS with which it hats been previously paired (CSt) produces a more diminished UR compared to a CS explicitly unpaited with the US (CS-), and (b) that preceding the US by a neutral simulus (NS), one not presented during the conditioning trials, produces a more diminished $U R$ than the $C S-$, but less than the $C S+$. The assumption underlying this prediction is that the NS does not possess associative properties, either excitatory or inhibitory.

\section{Method}

\section{Participants}

Participants were 61 undergraduate volunteer psychology students, ages ranging from $20-30$ years $(M=20.84, S D=$ 2.57). All received class credit for their participation in the experiment.

\section{Stinuli, Materials, and Apparatus}

The CS+ consisted of the image on a computer screen of a red square, measuring $7 \times 7 \mathrm{~cm}$, on a dark blue background. The CS- was also an image on a computer screen, this time, at red triangle of approximately the same size and displayed against the same color background as the CS+ squate. A red circle of similar characteristics as those of the CS was used as NS. The aversive US, white noise of $105 \mathrm{~dB}$ of intensity, was delivered through headphones. Heart rate was recorded on a Biopac MPLOOWS by means of a photoplethysmograph. The transductor was attached with velcro to the index finger of the participant's dominant hand. Stimulus onset and offset, interstimulus and intortrial intervals were control]ed by a PC compuler.

\section{Variables and Design}

The experiment was designed according to a repeated measures factorial model. The within-subject factors were:

Preceding stimulas: the levels of this factor were three: CS+, CS-, and NS, corresponding to the stimuli used in the testing phase.

Trial: with 5 levels, corresponding to the testing phase trìals.

Seconds of HR component: the number of levels of this factor varicd as a function of the component analyzed: $D I$ component, with 2 levels, corresponding to seconds 1 and 2 after CS onset; $A$ component, with 4 levels (seconds 3 to 6); $D 2$ component, with 3 levels (seconds 7 to 9), and $U R$, with 4 levels (scconds 10 to 13).

The heart rate amplitude elicited by each of the components analyzed (DI, A, D2 and UR) was used as dependent variable in each test trial, measured in beats per minute (bpm) and transiormed to differential scores (dHR).

\section{Procedure}

The experiment had four parts.

Phase of adaptation to the experimental situation: Once the apparatus was connected and the photoplethysmographic transductor had been altached, participants were rold that the purpose of the experiment was to measure consistency over time in response patterns to different stimuli (i.e., geometric shapes and bursts of white noise). At this point, three demonstration trials with only the burst of white noise were presented. Participants were told to remain calm and relaxed so that their level of activation would decrease and therefore not affect the subsequent heart rate recording.

Phase of habituation of the OR elicited by the CS and NS. The aim was to eliminate the possible OR produced by these stimuli before starting the conditioning trials. Fach participant was informed that only geometric figures would be presented during this phase. Each stimulus (square. triangle, and circle) was presented three times in permuted order, starting with the CS+.

Acquisition phase. In this phase, all participants were informed about the CS-US contingency. Specifically, they were told that from that moment on, the burst of white noise would always follow the presentation of the square (CS+) on the computer screen, but that it would never follow the triangle ( $\mathrm{CS}-$ ). This phase consisted of 30 presentations of $\mathrm{CS}+$ and $\mathrm{CS}-$, presented randomly with the restriction that no more than three consecutive CSs could be the same. The US was presented immediately following the termination of each CS+. Throughout the experiment, CS duration was $8 \mathrm{~s}$, and US duration was $0.5 \mathrm{~s}$. The intertrial intervals varied randomly between 25 and $35 \mathrm{~s}$ (offset of US to onser of next CS). To mitigate habituation and fatigue effects, the first conditioning session was ended after 20 trials. The next day, the other 10 trials were performed, thereby completing the acquisition phase.

Since the goal of this study was the analysis of the associative basis underlying the UR diminution, it was necessary, before starting the testing phase, to determine whether differential conditioning had occurred in the group. For this, the following criterion was used: The $A$ component amplitude should be significantly greater in the CS+/US condition than in the CS-/US condition in the last ten acquisition trials. Usually, the acceleration in response to the CS may be taken as an index of the conditioned response (Öhman, 1983).

Testing phase: When the 30 trials were completed, the testing plase was initiated. Each participant was instructed via the computer screen that, from then on, the burst of white noise (US) would follow all the geometric shapes presented (square, triangle, or circle), 8 seconds after stimulus onset. This way, awareness of the CS/US relationship and predictability of the US were controlled. This phase consisted of five presentations each of CS+, CS-, and NS followed by US. These 15 test trials were 
presented in a permuted order; thus, the US was never preceded by the same CS or NS two or more times consecutively. The duration of these CSs and NSs was the same as in the acquisition trials ( 8 s).

\section{Scoring and Data Analysis}

Mean heart rate for $D I, A$, and $D 2$ components were scored during the acquisition phase. In the testing phase. apart from these components, unconditioned responses (URs) were also scored. The intervals used for the CR components and the UR were already defined previously.

HR record was obtained, from the photoplethysmographic record, by means of the Biopac's Acknowledge software. Analogic-digital conversion of the HR record was performed for each participant and custom-made software to computc dHR scores was used. These scotes were calculated in each trial subtracting the mean $\mathrm{HR}$ value in each interval from the baseline corresponding to that trial.

Repeated measures analyses of variance (ANOVA) werc used to evaluate the reliability of effects on the amplitude of the HR responses. A rejection region of $p<.05$ was used for all main elfects and interactions. Greenhouse-Geisser epsilon corrections were uscd to adjust probabilities for repeated measules elfects (Jennings, 1987; Vasey \& Thayer, 1987). Tests of multiple mean differences were calculated using the a priori $t$-test formula, corrected for degrees of frcedom (Kirk, 1968).

ANOVAs were performed with the purpose of analyzing the evolution of the CR components and their possible influence on UR as a function of preceding stimulus. Threc Preceding Stimulus $\times$ Trial $\times$ Second ANOVAs were conducted for each CR component in the acquisition and testing phases. An additional ANOVA for UR, with the same factors, was carried out in the testing phase.

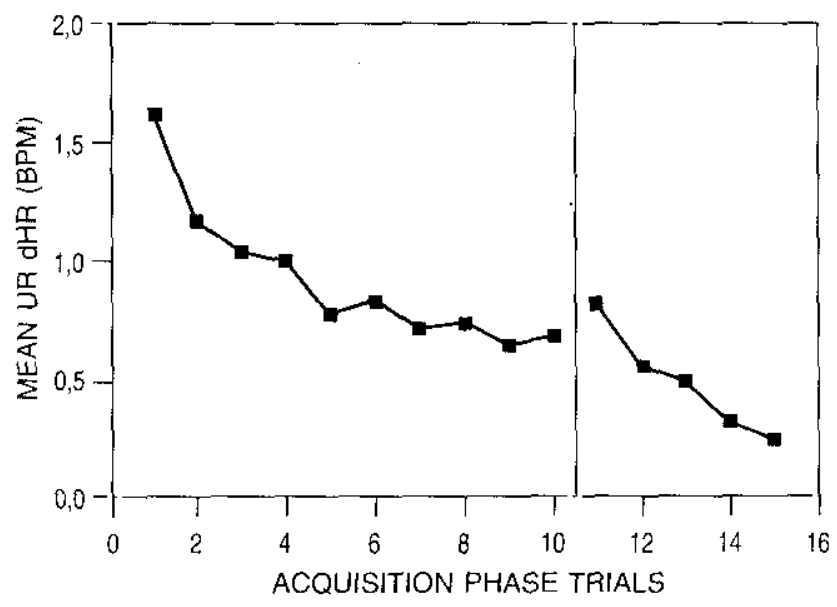

Figure 2. Evolution of mean dHR amplitude of the UR in the acquisition-phase trials (blocks of two trials). First ten blocks correspond to the first conditioning session and last five blocks to the second conditioning session.
Results

A $3 \times 3$ (stimulus $\times$ trial) ANOVA was performed to verify that the $O R$ elicited by the stimuli before starting the conditioning was the same. Results of this ANOVA showed that the main effect of trials was statistically signjficant, $F(2$, $60)=4.15, p<.05$, whereas the main effect of stimulus. $F(2,120)=.03, p>.05$, and the interaction between stimulus and trial, $F(4,240)=.10, p>.05$, were not signilicant. These results indicate that there is initial deceleration and subsequent habituation. This habituation shows a similat cvolution for the three stimuli, reaching the baseline in the third trial.

A second analysis was carried out to evaluate the UR evolution over conditioning trials. The course of the UR during the two sessions is shown in Figure 2, where an $\mathrm{HR}$ diminution can be observed. However, the analysis showed that the dimimution was not statistically sjgnificant in any scssion. No significant differences were found between the last trial block of the first session $(M=.69)$ and the first trial block of the second session $(M=.87), F(1,60)=7.78$. $p>.05$. The high intensity of the US (105 dB) probably prevented a significant UR habituation, with the aversive nature of the US persisting during conditioning sessions.

As can be seen in Figure 3, the ANOVA performed in the last ten trials of the acquisition phase to determine whether differential conditioning had occurred, showed that the main effect of stimulus for the $A$ component was statistically significant, $F(1,60)=7.48, p<.01$, mean $\mathrm{dHR}$ in the $A$ window being $0.59 \mathrm{bpm}$ for $\mathrm{CS}+$ and $-0.36 \mathrm{bpm}$ for CS-. Therefore, dilferential conditioning had occurred in the group (Öhman, 1983). Furthermore, the main effect of stimulus in the $D 2$ window was also significant, $F(1,60)$ $=8.02, p=.01$, mean $\mathrm{dHR}$ being $-1.64 \mathrm{bpm}$ for CS+ and $0.32 \mathrm{bpm}$ for CS-. No significant main effect or interaction in the $D$ l component were lound.

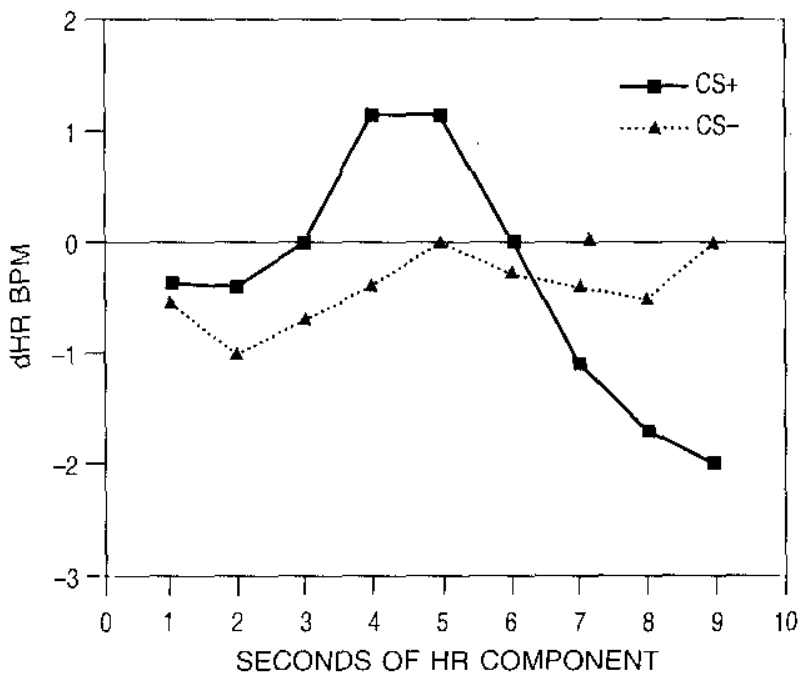

Figure 3. Mean dHR amplitude of the CR components eljcited by the $\mathrm{CS}+$ and $\mathrm{CS}$ - in the last ten triais of the acquisition plase. 


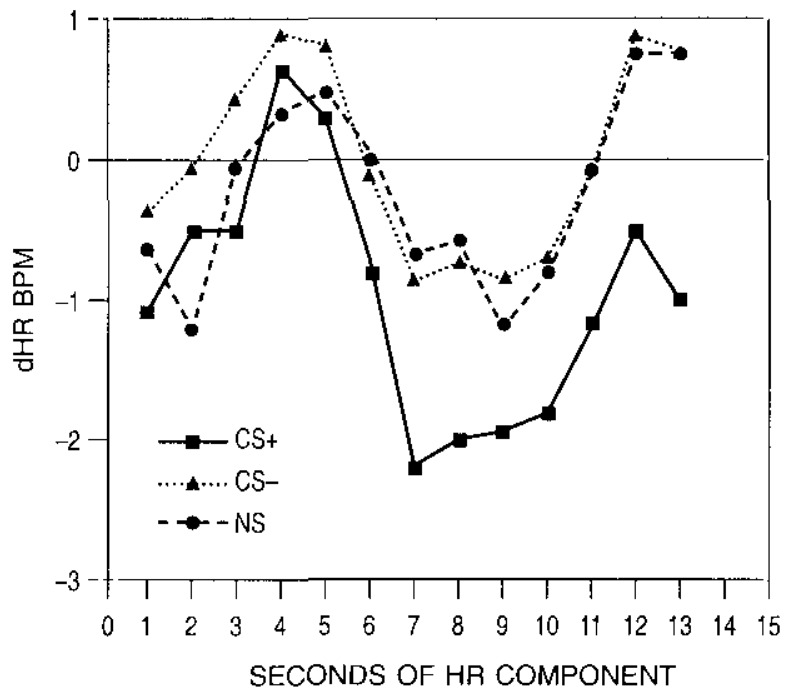

Figure 4. Mean dHR amplitude of the CR components and the UR elicited by the CS+/US, CS-/US and NS conditions during the testing phase.

As shown in Figure 4, the ANOVA performed in the testing phase on the $D /$ component did not show any significant main effect or interaction. The ANOVA for the $A$ component showed that the main effect of the second was significant, $F(3,180)=5.45, p<.01$, as expected due to the inverted $\mathrm{U}$ shape of this component. The $D 2$ component analysis showed a significant main effect of preceding stimulus, $F(2,120)=3.22, p<.05$. The multiple mean comparisons tests showed that the $D 2$ component was significantly lower when the US was preceded by the CS+ $(M=-2.02 \mathrm{bpm})$ than when preceded by the CS- $(M=-.82$ bpm) or the NS ( $M=-.88 \mathrm{bpm})$. However, no significant differences were found in this component between CS- AS and NS/US conditions. Lastly, UR analysis showed that the main effect of preceding stimulus was also significant, $F(2$, 120) $=4.93, p<.01$, the UR being significantly lower in the CS+/US condition $(M=-1.09 \mathrm{bpm})$, than in the CS-/US $(M=-.16 \mathrm{bpm})$ or NS/US ( $M=-.08 \mathrm{bpm})$ conditions. No significant differences were found in the UR between the CS-/US and NS/US conditions.

Although the interaction trials $\times$ preceding stimulus was not statistically significant, $F(8,480)=.25, p>.05$, it can be observed that the UR exhibits a different pattern over trials in the CS+/US condition with respect to the CS-/US and NS/US conditions (see Figure 5).

\section{Discussion}

Various explanations have attempted to interpret the UR diminution phenomenon. Thus, the OR reinstatement hypothesis (Badia \& Dcfran, 1970; Furedy \& KJajner, 1974; Grings, 1969), attempts to account for the difference in

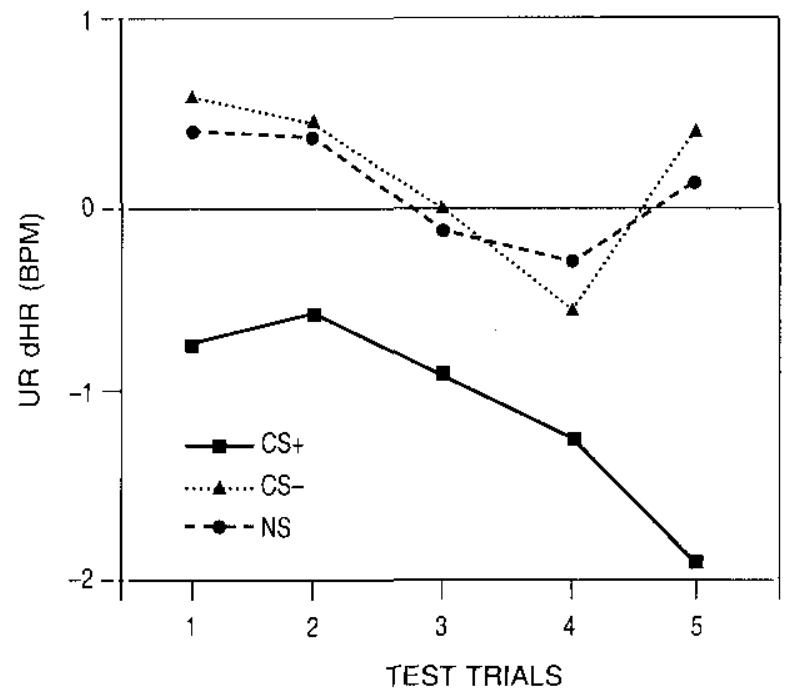

Figure 5. Evolution over test trials of mean dHR amplitude of UR in the CS+/US, CS-/US and NS/US conditions.

response magnitude between predictable and unpredictable aversive stimulus conditions. The unpredictable (or less predictable) aversive stimulus produces a response of greater magnitude simply because the less predictable a stimulus is, the greater is its novelty. In this experiment, CS+/US combination was presented 30 times during the acquisition phase, making the potential reinstatement of the OR in the test phase very unlikely. The CS-/US combination is new but at least the CS- had been presented frequently. By contrast, the NS was only presented 3 times in the first session during the adaptation phase, so when the NS/US combination is presented in the test phase, it appears as a more novel stimulus than the $\mathrm{CS}+/ \mathrm{US}$ and CS-/US combinations. Thus, according to this hypothesis, the NS/US condition should produce a greater reinstatement of the OR and, therefore, a greater amplitude of component $\mathrm{DI}$ and UR than the conditions CS+/US and CS-/US.

The results obtained by Marcos and Redondo (1999a) could be adequately explained as an OR reinstatement effect. However, the results obtained in the present study cannot be explained by this hypothesis. On the one hand, UR amplitude in the NS/US condition was statistically the same as in the CS-/US condition, and greater than the UR elicited by CS+/US. On the other hand, no significant differences were found in the $D /$ component amplitude among the three conditions of preceding stimulus, as would be expected from the OR hypothesis. However, this interpretation should be taken with caution, since there is some controversy about the utilization of the $D /$ component as an index of $O R$. Therefore, Barry (e.g., Barry, 1977, 1984, 1989; Barry \& Maltzman, 1985) has questioned the notion that DI HR deceleration is a measure of the OR. Barry (1984) bases his conclusion primarily on the following arguments: (a) HR 
deceleration does not demonstrate habitution rates anywhere comparable to SCR habiluation ratcs, and (b) HR deceleration is independent of stimulus manipulations; it is especially insensitive to stimulus change. Barry s conclusions concerning HR deceleration. especially his notion that decelerative $\mathrm{HR}$ responses do not habituate. have been scverely criticized by Turpin $(1983,1985,1986,1989)$. According to Turpin, Barry's failuse to observe habituation eflects (e.g., Barry, 1977, 1982) can be attributed to a number of methodological shortcomings (e.g., Barry, 1989; Simons, 1989; Turpin, 1989; Vossel \& Zimmer, 1989).

Another of the explanations formulated to interpret the UR diminution phenomenon was the preception hypothesis (Lykken, 1968; Lykken, Macindoe, \& Tellegen, 1972; Lykken \& Tellegen, 1974). This hypothesis states that temporal predictability of a US reduces its aversiveness. Accolding to this hypothesis, UR diminution occurs because of a phasic, selective inhibition process that reduces the arousal reaction to the US. This process is cognitively mediated by the warning-signal quality of the CS. This hypothesis has led to numerous studies and experiments. in which SCR was used in most (see Baltissen \& Boucsein. 1986; Furedy, 1970, 1975). The results obtained in the present study, however, cannot be accounted for by the preception hypothesis. The actual act of informing the participants at the beginning of the testing phase about the stimuli contingencies should result in a similar US predictability and, therefore, in a similar UR amplitude in the three conditions. However, the UR amplitude was significantly lower in the CS+/US condition than in the other two conditions. Nevertheless, the conditioning level in the three conditions was similar in the testing phase. since no significant differences were found in the $A$ component amplitude between the CSF/US, CS-/US and NS/US conditions. This result is coherent with the preception hypothesis, because it predicts that the appearance of a CR is contingent to the awareness of the CS/US relation that, in the testing phase, takes place by means of the information given to the participants. This interpretation about the effectiveness of the instructions given to the participants is supported by the fact that the amplitude of the $D$ / component is statistically the same in the three conditions.

Lastly, a third hypothesis assumes that the conditioned diminution of the UR has an associative basis (e.g., Baxter, 1966; Girings \& Schell, 1971; Kimmel, 1967; Kimble \& Ost, 1961; Kimmel \& Pennypacker, 1962). According to this hypothesis, diminished UR, seen in the presence versus the absence of a training CS, depends upon the integrity of the representation of the $\mathrm{CS}$. Various investigations (e.g.. Canli, Detmer, \& Donegan, 1992; Donegan \& Wagner, 1987 , Experiment 2; Marcos \& Redondo, 1999a, 1999b) seem to confirm a deteriorative effect of conditioning on the amplitude of the UR and suggest that the conditioned diminution phenomenon depends on the association of the CS with the US.
The two hypotheses formulated in this investigation aceept the assumptions of this last interpretation of UR diminution phenomenon. The results obtained in the testing phase indicute that the type of CS that precedes the US differentially affects the amplitude of the D2 component and of the UR. If the US is preceded by the CSt, UR amplitude exhibits a greater diminution than when the US is preceded by the CS-, which seems to confirm the first hypothesis of this study. This result is consistent with the interpretation that the CS+ produces an effect of UR diminution duc to its associative properties acquired by its repented association with the US. that is, through an excitatory conditioning process. However, the second hypothesis could not be conlirmed. It is possible that the preception effect is sufficiently important so as to cancel the inhibitory effect of $\mathrm{CS}$ in the testing phase. resulting it the absence of signilicant differences in the UR between the CS-/US and the NS/US conditions. However, in the CS+/US condition, the associative effect, which is the consequence of the prior CS+/US pairing, is added to this preception effect (that would simply confirm a previous contungency). This would result in a lower UR amplitude in the CS+/US than in the olher two conditions.

The results ohtained in the testing phase seem to indicate that the 122 component is responsible for UR diminution observed in the CS+/US condition. In fact, $D 2$ amplitude is also signiticantly lower when US is preceded by $\mathrm{CS}+$ than by CS- or NS. This result can be interpreted as a consequence of the excitatory conditioning (CS+/US) that occurred dering the 30 conditioning trials. As a result of the mentioned conditioning, the CS+ would allow the participant to prepare to receive the impact of the aversive US presented afterwated. This preparation would be achieved by a response antagonistic to UR, that is, by means of a $H R$ deccleration. This deceleration occurs right before the appearance of US and is manifested in the $D 2$ component, which seents logical from the adaptive point of view. In fact, the efficacy of the decelertive response would be greater the closer it is in time to UR. So, in the CS+/US condition, UR will begin at a lower bprn valuc than in the other two conditions, thus, the subsequent HR acceleration would also be lower.

It is worth noling, however, that this preparation effect of the 02 component is also produced and similarly in the CS-/US and NS/US conditions because, in both cases. UR, originates from a level that is below baseline. This result may be a consequence of the re-evaluation of the CS- and of the NS during the testing phase, outcome of the instructions received by the participants at the beginning of this phase, that cause the CS-- and the NS to acquime a signal value for the US, similar to the CS+. However, despite this similar US predictability, the $D 2$ component and the UR are significantly fower in the CS+/US condition, which seems to indicate that UR diminution is a result of prior conditioning.

The fact that the 02 component, in the acquisition phase, reaches values significantly lower in CS+/US condition than in control condition (mean $H R$ in the same $D 2$ latency 
window for $\mathrm{CS}_{-}$), is coherent with this interpretation. In fact, in CS+/US condition, D2 deceleration would have the adaptive function, as in the testing phase, of mitigating the impact of aversive US. Of course this does not occur in CS- condition, since $H R$ values do not deviate significantly from the baseline. Consequently, we bejicve that in CS/US preparations, in which US is aversive, the $D 2$ component could be used, in addition to the accelerative component, as an inclex of CR. The $A$ component is related to cognitive aspects of CS processing (Lacey, 1967; Öhman, 1983). The D2 component would be related to processes aimed at preparing to receive the aversive US. In HR conditioning, the D2 component is traditionally related to anticipation of an US (Bohlin \& Kjelberg, 1979; Hugdahl, 1995b) and is assumed to rellect anticipatory processes aimed at the detection of US (Kocrs et al., 1997). Thus, Heslegrave and Furedy (1977) found larger D2s when participants were more motivaled of were threatened by the possibility of an aversive event (shock). The results of the work presented here suggest that the $D 2$ component also plays an adaptive role, that is, to mitigate the impact of the subsequent aversive US by UR diminution.

\section{References}

Badia, P., \& Detran. R.H. (1970). Orjenting responses and GSR Conditioning: A dilemma. Psychological Review: 77, 171-181.

Baltissen, R. (1998). Psychophysiologische Reaktionen auf vorheragbare aversive Reize in verzoegerten Konditionierungsparadigma: Wiedereinsetzen der Orientierungsreaktion oder informatorische Kontrolle? Zeitwchrift fir Experimentelle Psychologie, 45, $29-41$.

Baitissen, R., \& Boucsein, W. (1986). Effects of a warning signal on reactions to aversive white noise stimulation: Does warning "short-circuit" habituation? Psychophysiology, 23, 224-231.

Barry, R.J. (1977). Failute to find evidence of the unitary OR concept with indifferent low-intensity auditory stimuli. Physiological Prwhology, 5. 89-96.

Batry, R.J. (1982). Novelty and significance effects in the fractionation of phasic $O R$ measures: $A$ synthesis with traditional OR theory. Pswhophysiology, 19, 28-35.

Barry, R.J, (1984), Preliminary processes in OR elicitation. Acta Psychologica, 5.5. 109-142.

Barry, R.J. (1989). Heat rate decelcration as an index of the orienting response: Comment on Vossel and Zimmer $\left(1989^{3}\right)$. Joumal of Pinchophysiology, 3, 225-228.

Barry. R.J., \& Maltzman. I. (1985). Heart rate deceleration is not an orienting reflex; heart rate deceleration is not a defensive ref]ex. Ponleviom Journal of Biological Science, 20, 15-28.

Baxter, R. (1966). Diminution and recovery of the UCR in delayed and trace classical GSR conditioning. Joumal of Experimental Psychology, 7/, 447-451.

Bohlin, G., \& Kjellherg. A. (1979). Orienting activity in twostimulus paradigms as reflected in heart tate. In H. D. Kirnmel, E.H. van Olst. \& I.F. Orlebeke (Eds.). The orienting reflex in Inumans (pp. 169-198). Hillsdale, NJ: Erlbaum.
Canli, T.. Detmer, W.M., \& Donegan, N.A. (1992). Potentiation or diminution of discrete motor unconditjoned responses (rabbit eycblink) to an aversive Pavlovian unconditioned stimulus by two assuciative processes: Conditioned fear and conditioned diminution of unconditioned stimulus processing. Behavioral Nenroscience, 100, $498-508$.

Donegan, N.H., \& Wagner, A.R. (1987). Conditioned diminution and facilitation of the UR: A sometimes opponent-process inteppretation. In 1. Gormezano, W.F. Prokasy, \& R.F. Thompson (Lds.), Classical conditioning III (pp. 339-369). Hillsdale, NJ: Erlbaum.

Furedy, J.J. (1970). Test of the preparatory adaptive response interpretation of aversive classical autonomic conditioning. Joumal of Experimental Psychology, 84, 301-307.

Furedy, J.J. (1975). An integrative progress report on informational control in humans: Some laboratory findings and methodological claims. Australian Joumal of Psychology 27 . 6] -83 .

Furedy, J.J. (1992). Rellections on human Pavlovian decelerative heart-rate conditioning with negative tilt as US: Altenative approaches. Integrative Physiological and Behavioral Science, 27. $347-355$.

Furedy, J.J., \& Klajner, F, (1974), On evaluating autonomic and verbal indices of negative preception. Psychophysiolog., $/$, $121-124$.

Graham, F.K. (1973). Habituation and dishabituation of responses innervated by the autonomic nervous system. In H.S. Peake \& M.J. Hertz (Eds.), Habitration (Vol. 1. pp. 163-218). New York: Academic Press.

Grings, W.W. (1960). Preparatory set variables related to classical conditioning of autonomic responses. Prychological Review, 67. $243-252$.

Grings, W.W. (1969). Anticipatory and preparatory electrodermal behavior in paired stimulation situations. Psychophysiology, 5 , 597-611.

Grings. W.W., \& Schell, A.M. (197I). Effects of trace versus delay conditioning, interstimulus interval variability and instructions on LiCR diminution. Joumal of Experimental Psychology, 90. 130-140.

Heslegrave, R.J., \& Furedy, J.J. (1977, October). Anticipatory $H K$ decelcration: The offects of active versus passive coping and the probutility of negative reinforcement. Abstract from paper presented at the Meeting of the Society for Psychophysiological Research, Philadelphia. PA.

llugdahl, K. (1995). Psychophysiology: The mind-body perspective (pp. 197-233). Cambridge, MA: Harvasd University Press.

Hugdahl, K. (1995b). Classical conditioning and implicit learning: The right hemisphere hypothesis. In R.J. Davison \& K. I lugdahl (Eds.), Brain asymmetry (pp. 235-267). Cambridge, MA: MIT Press.

Jennings. J.R. (1987). Editorial policy on analysis of variance with repeated measures. Psychophysiology 24, 474-475.

Kimble, G.A.. \& Ost, J.W.P. ([961). A conditioned inhibitory process in eyelid conditioning. Joumal of Experimental Psychology, 61. 150-150. 
Kimmel, H.D. (1966). Inhibition of the unconditioned response in classical conditioning. Psychological Review, 73, 232-240.

Kimmel, E. (1967). Judgments of UCS intensity and diminution of the UCR in classical GSR conditioning, fournal of Experimental Psychology, 73, 532-543.

Kimmel, H.D. \& Pcnnypacker, II.S. (1962). Conditioned diminution of the unconditioned response as a function of the number of reinforcements. Joumal of Experimental Prychology, 64, 20-23.

Kirk, R. E. (1968). Experimental design: Procedures for the hehavional sciences. Belmonl. CA: Brooks Cole.

Koers, G., GHlard, A.W.K., \& Mulder, G. (1997). Evoked heart rate and blood pressure in an S1-S2 paradigm. Biological Psychology, 46, 247-274.

Lacey, J.I. (1967). Somatic response patterning and stress: Some revisions of activation theory. In M. H. Appley \& R. Trumbuli (Eds.). Psychological stress: Issues in research (pp. 14-37). New York: Appleton-Century-Crofts.

Lykken, D.T. (1959). Preliminary observations concerring the "preception" phenomenon. Psychophysiological Measurements Newsletter, 5, 2-7.

Lykken, D.T. (1968). Neurophysiology and psychophysiology in personality rescarch. In E.F. Borgatta \& W.W. Lambert (Eds.). Handbook of personality researh (pp. 413-509). New York: Rand McNally.

Lykken, D.T., \& Tellegen. A. (1974). On the validity of the preception hypothesis. Psychophysiology, M, 125-132.

Lykken, D.7., Macindoc, Y.. \& Tellegen, A. (1972). Preception: Autonomic responses to shock as a function of predictability in time and locus. Psychophysiology, 9, 318-333.

Marcos, J.L. (1997). Técnicas de condicionamieno hmano. Madrid: Universitas.

Marcos, J.L., \& Redondo, J. (1999a). Effects of conditioned stimulus presentation on diminution of the unconditioned response in aversive classical conditioning. Biological Psychology, 50, 89102.

Marcos, J.L., \& Redondo, J. (1999b). Effects of CS-US interval modification on diminution of the unconditioned response in electrodermal classical conditioning. Biological Psychology. 50, $191-201$.

Obrist, P.A., Webb, R.A., \& Sutterer, J.R. (1969). Hent rate and somatic changes during aversive conditioning and a simple reaction time task. Psychophysiology, 5, 696-723.

Ohman, A. (1983). The orienting response during Pavlovian conditioning. In D. Siddie (Ed.), Ortenting and hatratuion. Perspectives in haman research. Chichester. UK: Wiley.
Otten, L.J., Gaillard, A.W.K., \& Wientjes, C.J.E. (1995). The relation between event-related bain potential. heart rate. and blood pressure in an S1-S2 paradigm. Biological Psychology, 39. $81-102$.

Redondo. J.. \& Marcos, J.L. (2000). Efecto de la interferencia de respuesta sobre la disminución de la respuesta electroclérmica incondicionada. Psicothoma, 72 . 125-129.

Simons, R.F. (1989). "A rose by any other name": A comment on Vossel and Zimmer, Journal of Psychophysiology, 3. 125 127.

Taylor, J., Carlson, S.R.., Iacono, W.G.. Lykken, D.T., \& McGuc, M. (1999). Individual differences in electrodermal responsivity to predictable aversive stimuli and substance dependence. Pxychophysiology, 36, 193-198.

Turpin. G. (1983). Unconditioned reflexes and the autononic nervous systcm. In D.A.T. Siddle (EL), Orioning and habithation: Perpectives in haman researh (pp. 1-70). Chichester. UK: Wiley.

Turpin. 0 . (1985). The efrects of stimulus intensity on cardiovascular acivity: The jroblem of differentiating orienting. defonse and startle responses. In J.F. Orlcbeke. G. Mulder. \& L.J.P. Van Doomen (Eds.), Pryfophysiology of cardionascalar control: Models, methods, and data (pp. 621-(36). New York: Plenum Press.

Turpin. G. (1986). Effects of stimulus intensity on atonomic responding: The problem of differentiating orienting and defense reflexes, Prwhophyology, 23, 1-14.

Turpin, G. (1989). An adcquate test of the habituation of the cardiac decelerative responsc component of the oricnting reflex: Necessary conditions and sufficient evidence. A comment on Vosscl and Zimmer. Jom of Psychophwiology, 3. $129-140$.

Vasey, M.W.. \& Thayer. J.F. (1987). The continuing problem of lalse positives in repeatod moasures ANOVA in psychophysiology: A multivariate solution? Psychophysiology. 24. 479-486.

Venables, P I1. (1991). Autonomic activity. Anats of the New York Academy of Sciences, 620, 191-207.

Vossel, G., \& Zimmer, H. (1989). "Roses have thorns and silver fountains mud": A reply to Simons and Turpin. Journal of Psychophsiology, 3, 141.140.

Received July 13, 2000 Revision received November 10,2000 Accepted January 4, 2001 